\title{
IS THERE A RELATIONSHIP BETWEEN SELF-EFFICACY, WELL-BEING AND BEHAVIOURAL MARKERS IN MANAGING STRESS AT UNIVERSITY STUDENTS?
}

Ludmila Natovová, Hana Chýlová

Czech University of Life Sciences Prague

\author{
Highlights \\ - Subject with lower level of vulnerability to stress experience probably higher level of well-being \\ - People with higher self-efficacy prefer healthier life-style
}

\section{Abstract}

Article type

This paper addresses the question of mutual relationship of the perceived self-efficacy, well-being and particular health-promoting behaviours in respondents - students of the Faculty of Economics and Management of the Czech University of Life Sciences. A descriptive, correlational research design was conducted. The Czech version of the General Self-Efficacy Scale GSES, Czech version of the Satisfaction with Life Scale SWLS and Czech version of Stress Vulnerability Scale was administered to 211 undergraduate students from September to October 2013. Having tested normal distribution of each variable via Kolmogorov-Smirnov and Shapiro-Wilk test, our statistical analysis was based on the calculation of values of the nonparametric Spearman's rank correlation coefficient. Results show significant correlations between all of examined variables. In terms of the examined variables, selfefficacy, behavioural markers connected to vulnerability to stress and well-being in particular appear to be meaningful concepts that can be well used in education and counselling related to coping with stress during university studies.

\section{Keywords}

Behaviour, Self-efficacy, Stress, University students, Well-being

Natovová, L. and Chýlová, H. (2014) "Is There a relationship between Self-efficacy, Well-being and Behavioural Markers in Managing Stress at University Students", Journal on Efficiency and Responsibility in Education and Science, Vol. 7, No. 1, pp. 14-18, online ISSN 1803-1617, printed ISSN 2336-2375, doi: 10.7160/eriesj.2013.070302.

\section{Introduction}

Questions on student progression and student retention have increasing importance for most universities. This is the reason why researchers have taken interest in the issues of perceived stress, academic load associated with study, coping strategies, as well as various behaviours associated with stress, such as the development of alcohol and drugs addiction, changes in everyday activities, sleep regime or food intake (Kausar, 2010; Digdon, Landry, 2013; Robotham, Julian, 2006). Authors of this study have already dealt with the issue of self-efficacy and coping strategies in university students in their previous studies (Natovová et al, 2013; Chýlová, Natovová, 2013). Our previous research work was focused on the field of age and gender differences in coping strategies adopted by university students (Natovová, Chýlová, 2012). Lazarus (1999: 102) defines coping as activities, which have "...to do with the way people manage life conditions that are stressful". Other authors (Tanaka, 2009: 87) define coping as a term “...referring to the cognitive or behavioural efforts used to manage, reduce, or control stress". With respect to coping, emotion-oriented, task-oriented and avoidance-oriented stress coping activities are commonly distinguished (Aldwin and Yancura, 2011), or groups of positive, negative and neutral coping strategies can be identified and measured by psychodiagnostic tools (Janke and Erdmann, 2003).

According to the results of the research on coping we broadened the area of our interest and tried to define a relationship between perceived self-efficacy, groups of coping strategies and specific behaviours that can contribute to higher vulnerability to stress. In our sample of students, a correlation has been found between behaviour strategies increasing stress vulnerability and the second groups of coping strategies. We have ascertained that vulnerability to stress in terms of behaviours significantly negatively correlates $(\rho=-0.41)$ with strategies of distraction and substitute gratification, while self-efficacy significantly positively correlates with positive coping strategies in general ( $\rho=0.56$ ), as well as with coping strategies of minimization and denial of guilt $(\rho=0.48)$ and of situation control, response control and positive self-instructions $(\rho=0.53)$. By contrast, in case of self-efficacy we have found statistically significant negative correlation with negative coping strategies $(\rho=-0.71)$. Therefore we assume that effective coping in connection with higher level of self-efficacy relates also to individual's perceived satisfaction with life and leads to health-promoting behaviour. This paper follows and elaborates on previous research work in this field.

We have therefore attempted to cover the issue of stress coping in a comprehensive way, focusing, in addition to coping strategies, also on a potential link to the study of self-efficacy and on any particular behavioural indicators associated with increased or decreased vulnerability to stress. The main aim of this study is to find an answer at the question whether there is a correlation between the perceived self-efficacy, particular health-promoting behaviours and the level of well-being in respondents - students of the Faculty of Economics and Management of the Czech University of Life Sciences. In order to understand the interrelations, first we need to clarify how the research constructs are defined.

The concept of self-efficacy was created by Albert Bandura, founder of the social cognitive theory. Defining this concept, Bandura (1997: 3) says that "perceived self-efficacy refers to 
beliefs in one's capabilities to organise and execute the courses of action required to produce given attainments". Jerusalem and Schwarzer (1992) claim that generalized self-efficacy is one of the personal resource factors that counterbalance taxing environmental demands in the stress appraisal process, within which stress can be cognitively appraised as either a challenge, threat, or harm/loss; in subsequent stage of stress coping dispositional self-efficacy facilitates coping with stress. Warner et al. (2011) note that besides one's general confidence in one's ability to manage demands placed on them and achieve one's goals, perceived self-efficacy may also differ with regard to specific life spheres and problems encountered. General resources for enhancing self-efficacy include mastery experience, vicarious experience, verbal persuasion, and somatic and affective states (Bandura, 1997; Warner et al., 2011). Loeb, Steffensmeier and Kassab (2011: 812) hypothesize that there exists a relationships between self-efficacy and health behaviours, both health-promoting and health-monitoring. These authors (Loeb, Steffensmeier, Kassab, 2011; Bandura, 1997) assume that higher perceived self-efficacy in relation to health-promoting behaviours results in improved health. Lipke et al. (2009) conducted study on the putative moderating role of self-efficacy in the intention-planning-behaviour relationship (physical activity). They concluded that self-efficacy moderates the mediation of intentions into behaviour via plans, that people must hold sufficiently high levels of self-efficacy. This study therefore also focuses on this aspect; namely on identifying vulnerability to stress with respect to specific behaviour factors (smoking, sports activities, leisure time activities, etc.). In this study we have attempted to measure and to quantify several essential components of healthy life style (frequency of aerobic exercise, social activities, food intake regime, smoking and alcohol drinking etc.).

Subjective well-being (SWB) is, according to Diener (2000), people's cognitive and affective evaluation of their lives. Elsewhere Diener (1994) states that subjective well-being comprises people's longer-term levels of pleasant affect, lack of unpleasant affect, and life satisfaction. The concept displays moderately high levels of cross-situational consistency and temporal stability. Well-being is frequently assessed as a part of the concept of so called "quality of life", which is usually expressed as a combination of mutually interconnected factors: well-being, subjective assessment of one's health condition and life satisfaction. Even though some authors consider well-being to be a key factor and recommend to standardly monitor it in various contexts (Kebza, 2005).

Diener et al. (1985) claim that it is possible to isolate various components of subjective well-being: affective, emotional aspects (positive and negative affects) and cognitive, judgemental aspects - life satisfaction. Judgment of life satisfaction is dependent upon a subjective comparison of one's circumstances with what one considers to be the appropriate standard. Diener and Diener (1996), in their article "Most People Are Happy", hypothesise that people might be motivated to attain positive states and to avoid or reduce unpleasant states and therefore may be likely to use positive coping strategies and, as a result, be mainly happy.

In his recent studies Diener (Nickerson, Diener and Schwarz, 2011 or Diener et al., 2002) paid attention to the relation between positive affect and college success, respectively job outcomes. Last year Diener (2012) described newest important findings on worldwide subjective well-being, namely benefits in health, longevity, citizenship, and social relationships as a result of high subjective well-being.

Proceeding from the theoretical background described above, the main goal of this study is to determine whether a correlation can be found between subjective evaluation of life satisfaction - state of well-being of a person, perceived self-efficacy and behavioural indicators of vulnerability to stress of full-time and part-time students of the Faculty of Economics and Management (FEM) of the Czech University of Life Sciences (CULS).

\section{Materials and Methods}

\section{Group of respondents}

A descriptive, correlational research design was conducted from September to October 2013. The Czech version of the General Self-Efficacy Scale (Křivohlavý, Schwarzer and Jerusalem, 1993), Czech version of the Satisfaction with Life Scale (Diener et al., 1985) and Czech version of Stress Vulnerability Scale (Schreiber, 2000) was administered to 211 undergraduate students from September to October 2013. The target population of the present study was full-time and part-time students at the Faculty of Economics and Management (FEM) at the Czech University of Life Sciences (CULS) within the study programmes Economics and Management and Regional Development in distance-studies centre in Hradec Králové and in Prague. Descriptive characteristics of the sample are shown in Tab. 1.

The subjects volunteered to participate in the survey and received no benefits for their participation.

\begin{tabular}{|c|c|c|c|c|c|c|c|c|}
\hline & Z & $\partial^{0}$ & 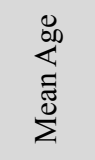 & 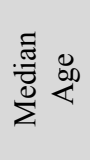 & 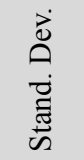 & $\begin{array}{l}\stackrel{0}{\infty} \\
\dot{\Xi} \\
\dot{\Xi}\end{array}$ & 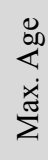 & 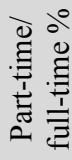 \\
\hline $\begin{array}{l}\text { Male } \\
\text { students }\end{array}$ & 77 & 36.5 & 22.82 & 20.00 & 7.81 & 17 & 64 & $\begin{array}{l}21.8 / \\
78.2 \\
\end{array}$ \\
\hline $\begin{array}{l}\text { Female } \\
\text { students }\end{array}$ & 134 & 63.5 & 28.09 & 23.00 & 10.16 & 18 & 51 & $\begin{array}{l}56 / \\
44 \\
\end{array}$ \\
\hline Total & 211 & 100 & 26.2 & 20.00 & 9.7 & 17 & 64 & $\begin{array}{l}43 / \\
57\end{array}$ \\
\hline
\end{tabular}

Tab. 1: Descriptive characteristics of subgroups of respondents.

\section{Assessment Measures}

Assessment in this study comprised three parts: measurement of perceived self-efficacy with Czech version of the General Self-Efficacy Scale (GSES), mapping of behavioral markers connected with higher vulnerability to stress via Stress Vulnerability Scale (SVS) and assessment of individual life satisfaction and pleasant feelings - well-being with Czech version of the Satisfaction with Life Scale (SWLS).

General Self-Efficacy Scale (GSES) consists of 10 statements measuring the efficiency of one's own action and perceived ability to manage problems on a four-point Likert-type scale. Possible score ranges from 10 to 40 points, and administration takes about four minutes. In this research work, we have used the original scale adapted for the Czech language (Křivohlavý, Schwarzer and Jerusalem, 1993). Typical items are e.g. "I can always manage to solve difficult problems if I try hard enough" Or "I can solve most problems if I invest the necessary effort".

Similarly, the Stress Vulnerability Scale (SVS) scale contains 20 items arranged in a 5 point Likert-type scale. It entails degrees ranging from 1 (always) to 5 (never) respectively and the subject had to rate each item according to how much of the time the 


\section{Natovová and H. Chýlová - ERIES Journal vol. 7 no. 1}

statement was true of him/her. Students were administered a Czech version of this scale, published in Czech by Schreiber (2000). Typical items of SVS scale are: "I give and receive affection regularly", "I eat at least one hot, balanced meal a day" or "I am able to speak openly about my feelings when angry or concerned".

The Satisfaction With Life Scale (SWLS) is a scale designed by Diener et al. (1985) to measure global life satisfaction. The SWLS consists of 5-item scales, where participants indicate how much they agree or disagree with each of the items using a 7-point scale that ranges from 7 (strongly agree) to 1 (strongly disagree) (Diener et al., 1985). Scale includes items like "In most ways my life is close to my ideal" or "So far I have gotten the important things I want in life". Pavot and Diener (2008) refer to the favourable psychometric properties of SWLS, including its high internal consistency and high test-retest reliability (0.82), Cronbach's alpha 0.87 . Satisfaction with life scales are frequently used as indicators of well-being.

\section{Statistical Analysis}

This research aims to determine whether a correlation exists between the variables self-efficacy (GSES index), vulnerability to stress associated with individual's behaviours (SVS index) and subjective well-being (SWLS index). First we tested normal distribution of each variable. In all cases we have rejected the null hypothesis on normal distribution of these variables based on general Kolmogorov-Smirnov and also more powerful Shapiro-Wilk normality tests. Results of these tests are displayed in Tab. 2.

\begin{tabular}{|l|c|c|c|c|c|c|}
\hline & \multicolumn{3}{|c|}{ Kolmogorov-Smirnov } & \multicolumn{3}{c|}{ Shapiro-Wilk } \\
\cline { 2 - 7 } & Statistic & df & Sig. & Statistic & df & Sig. \\
\hline GSES & 0.09 & 211 & $0.00^{*}$ & 0.99 & 211 & $0.03^{*}$ \\
\hline SVS & 0.08 & 211 & $0.00^{*}$ & 0.97 & 211 & $0.00^{*}$ \\
\hline SWLS & 0.10 & 211 & $0.00^{*}$ & 0.98 & 211 & $0.00^{*}$ \\
\hline
\end{tabular}

Tab. 2: Tests of Normality.

With respect to the specifics of the distribution of all variables mentioned above, we proceeded from the calculation of the nonparametric Spearman's rank correlation coefficient.

\section{Results}

Data was analyzed using descriptive and inferential statistics described in previous section. As we mentioned in the beginning, in this study we focused on the identification of potential correlations between perceived level of self-efficacy, vulnerability to stress in terms of behavioural indicators and subjective satisfaction in life and positive affectivity - subjective evaluation of well-being.

To make relationships between all variables clear and understandable, we have to describe the specifics of each variable in our research sample separately. Tab. 3 shows descriptive characteristics of general self-efficacy. In our previous study the mean value of Self-efficacy - GSES index was 29.66 (Chýlová, Natovová, 2013), and values shown in Tab. 3 correspond with this trend.

\begin{tabular}{|l|c|c|c|c|c|}
\hline & N & $\begin{array}{c}\text { Mean } \\
\text { GSES }\end{array}$ & Stand. Dev. & Min. & Max. \\
\hline Male students & 77 & 29.73 & 4.38 & 14 & 40 \\
\hline Female students & 134 & 28.55 & 4.48 & 17 & 38 \\
\hline Total & 211 & 28.98 & 4.47 & 14 & 40 \\
\hline
\end{tabular}

Tab. 3: Descriptive statistics of Self-efficacy - GSES index.
Values of Self-efficacy index differ significantly from other groups of respondents as for example from entrepreneurs, students from other Czech universities or German students (Chýlová, Natovová, 2013), but are relatively stable across our research work on various samples of our students. It is still a question, what are the causes for this fact and how it could be used it in education and also in personal development of our students during their studies at our faculty.

Tab. 4 shows descriptive characteristics of behavioural indicators connected to vulnerability to stress (SVS index) in our research. When looking at vulnerability to stress measured via behavioural markers displayed in Tab. 4, we see slight difference between male and female students.

\begin{tabular}{|l|c|c|c|c|c|}
\hline & N & $\begin{array}{c}\text { Mean } \\
\text { SVS }\end{array}$ & $\begin{array}{c}\text { Stand. } \\
\text { Dev. }\end{array}$ & Min. & Max. \\
\hline Male students & 77 & 23.04 & 8.30 & 9 & 59 \\
\hline Female students & 134 & 24.64 & 6.74 & 7 & 43 \\
\hline Total & 211 & 24.06 & 7.37 & 7 & 59 \\
\hline
\end{tabular}

Tab. 4: Descriptive statistics of Vulnerability to Stress - SVS index.

In general, values of SVS index less than 30 points show relatively appropriate behaviour patterns, which don't increase the vulnerability to stress. Answering the question about possible differences in several age and gender different groups deserves thorough independent research and will be analysed in a subsequent study.

The third variable which we took into account in present study is subjective well-being. Average values of SWLS index in common population are $19-24$ points. Our values correspond with this trend and are displayed in Tab. 5. Also in this case we can observe slight difference between male and female subgroups, but deeper analysis is required and will be processed in our future research work.

\begin{tabular}{|l|c|c|c|c|c|}
\hline & N & $\begin{array}{c}\text { Mean } \\
\text { SWLS }\end{array}$ & $\begin{array}{c}\text { Stand. } \\
\text { Dev. }\end{array}$ & Min. & Max. \\
\hline Male students & 77 & 23.23 & 5.58 & 11 & 35 \\
\hline Female students & 134 & 24.05 & 5.63 & 9 & 35 \\
\hline Total & 211 & 23.74 & 5.61 & 9 & 35 \\
\hline
\end{tabular}

Tab. 5: Descriptive statistics of well-being - SWLS index.

As we presented above, the main aim of this study is to find an answer to the question whether there is a correlation between the perceived self-efficacy, particular health-promoting behaviours and the level of well-being in respondents - students of the Faculty of Economics and Management of the Czech University of Life Sciences. Results of the calculation of Spearman's rank correlation coefficients are shown in Tab. 6.

\begin{tabular}{|c|c|c|c|c|c|}
\hline & & & $\begin{array}{l}\text { GSES } \\
\text { index }\end{array}$ & $\begin{array}{l}\text { SVS } \\
\text { index }\end{array}$ & $\begin{array}{l}\text { SWLS } \\
\text { index }\end{array}$ \\
\hline \multirow{9}{*}{ 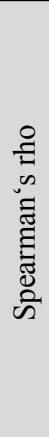 } & \multirow{3}{*}{ 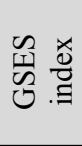 } & Correlation Coefficient & 1.000 & $-0.32 * *$ & $0.27 * *$ \\
\hline & & Sig. (2-tailed) & . & 0.00 & 0.00 \\
\hline & & $\mathrm{N}$ & 211 & 211 & 211 \\
\hline & \multirow{3}{*}{$\sum_{\infty}^{\infty} \frac{x}{0}$} & Correlation Coefficient & $-0.32 * *$ & 1.00 & $-0.27 * *$ \\
\hline & & Sig. (2-tailed) & 0.00 & . & 0.00 \\
\hline & & $\mathrm{N}$ & 211 & 211 & 211 \\
\hline & \multirow{3}{*}{$\sum_{\infty}^{\infty} \frac{x}{0}$} & Correlation Coefficient & $0.27 * *$ & $-0.27 * *$ & 1.00 \\
\hline & & Sig. (2-tailed) & 0.00 & 0.00 & . \\
\hline & & $\mathrm{N}$ & 211 & 211 & 211 \\
\hline
\end{tabular}

**. Correlation is significant at the 0.01 level (2-tailed).

Tab. 6: Values of Spearman's correlation coefficient. 
Several important findings are apparent when observing the results shown in Tab. 6. Our previous research (Natovová et al., 2013) has not confirmed a correlation between stress vulnerability in terms of behaviours and self-efficacy. In contrary, our results displayed in Tab. 6 show significant correlations between all of our variables.

\section{Discussion}

First examined variable was self-efficacy, in Tab. 6 as GSES index. Self-efficacy is a strong concept and Bandura (1997) generally presumes that people who have confidence in their ability to efficiently achieve their goals are also healthier, more successful and more effective. These people are also likely to experience a lower level of stress, similarly to the conclusions of Lazarus (1999: 102) “...when coping is ineffective, the level of stress is high; however, when coping is effective, the level of stress is apt to be low". In our previous study we identified correlations between coping strategies and self-efficacy (Natovová et al., 2013). According to our results people who have confidence in their ability to manage everyday problems and concerns in an effective and efficient way are also more likely to use positive coping strategies (including the three most effective coping strategies of situation control, reaction control and positive self-instructions, see Janke and Erdmann, 2003). At the same time, higher perceived self-efficacy may predict lower use of negative coping strategies. This fact probably explains positive correlation $(\rho=0.27)$ between general self-efficacy and subjective well-being. People who consider themselves capable and effective to handle with difficulties and problems in their lives have according to our findings higher satisfaction in life, commonly described as the feeling of subjective well-being. On the other hand, we can observe clearly negative correlation ( $\rho$ $=-0.32$ ) between self-efficacy (GSES index) and health-related behaviour connected to vulnerability to stress, in Tab. 6 the SVS index. People with higher self-efficacy probably prefer healthier life-style compared to people with lower self-efficacy level. This fact corresponds with findings of Bandura (1997), Lazarus (1999) and others. On the other hand, the SVS scale is general and further examination of the data, probably also intensive item analysis, would give more insight into behavioural patterns (social support items, sports, sleep and food intake regime etc.). Speaking about behavioural patterns connected to stress vulnerability, we need to take into account also relationships discussed in our previous work (Natovová et al., 2013, Chýlová and Natovová, 2013). First, stress vulnerability in terms of behaviours (expressed by the value of SVS) significantly negatively correlates with a group of positive coping strategies (Janke and Erdmann, 2003), which includes the strategies distraction - distract from stress related activities/situations or turn to stress incompatible ones a substitute gratification - turn to positive activities/situations (Natovová et al., 2013). In this case, we can state that higher vulnerability to stress may be associated with decreased pursuit of activities that are incompatible with stress or decreased pursuit of fulfilment in other areas except for the stress-related area. The relationship between vulnerability to stress and the use of distraction and substitute gratification strategies should be discussed in the sphere of counselling and teaching, because more frequent use of these strategies may lead to broader changes in behaviour and lower vulnerability to stress.

In Tab. 6 we can observe also a negative correlation $(\rho=-0.27)$ between behavioural markers connected to vulnerability to stress (SVS index) and subjective well-being (SWLS index).
Respondents with lower level of vulnerability to stress probably experience positive feelings and subjective satisfaction with life - they experience probably higher level of well-being. Issues of well-being and his impact at several life areas for university students are broadly discussed and examined and our results support the knowledge from different authors. Bozoglan, Demirer and Sahin (2013) investigated the relationship between well-being, loneliness, coping, decision styles and decision self-esteem and found out, that loneliness, self-esteem, and life satisfaction (well-being) explained $38 \%$ of the total variance in Internet addiction. Eroğlu (2012) considers well-being as an indicator of life quality, achievement of subjective aims, handling of difficulties of life and having pleasure of life. Samuel, Bergman and Hupka-Brunner (2013) say that well-being may serve as an individual resource by fostering educational and occupational outcomes. Van Petegem et al. (2008) claim, that student well-being can be considered a major output indicator of quality of education. The importance of the topic of well-being in university study seems obvious and has an important place also in broader context of responsibility in education.

Results presented in this research paper are inspiring also for deeper analysis, as we pointed above. Significant correlations provide information about the relationship between variables, but don't answer questions about causality. Further data analysis, for example regression analysis and testing of appropriate theoretical models, can provide more insight into causality of these variables in our future research work.

\section{Conclusion}

In this research, we considered a link between perceived selfefficacy, subjective well-being and specific behaviours that can contribute to higher vulnerability to stress. In our sample of students, a correlation has been found between all of the variables (self-efficacy as GSES index, vulnerability to stress as SVS index and well-being as SWLS index). This correlation is understandable, stemming from the concepts introduced above, and this fact needs to be taken into consideration in the sphere of teaching and counselling.

As we mentioned above, in our previous research we have identified relations between the level of perceived self-efficacy and most groups of coping strategies (positive, negative, as well as the first and third subgroups of positive coping strategies as distinguished by Janke and Erdmann, 2003). Self-efficacy therefore appears to be a meaningful concept that can be well used in education and counselling related to coping with stress. States of uncertainty regarding important issues (e.g. stressful life events, which students can experience in personal and social life during university studies) throw people into a state of confusion: those who are capable of modifying the course of events significantly are equally capable of foreseeing them (D'Amico et al., 2013). Topics and activities oriented on increasing of self-efficacy of our students can lead to increased satisfaction with life and can also be related to health-promoting behaviour.

Our intended future research work in this area should be outlined here. The research should focus on various spheres of work and private life and the perception of such specific selfefficacy (e.g. self-efficacy in relation to study, self-efficacy in relation to sports activities, self-efficacy in partnership, etc., as mentioned by Bandura, 1997, for example). For the purpose of education and psychological counselling at CULS, possibilities of training activities aimed at enhancing perceived self-efficacy in students of the Faculty of Economics and Management of the 
Czech University of Life Sciences should also be considered in order to heighten the level of satisfaction with life - subjective well-being.

\section{Acknowledgements}

This research was supported by the project CIGA CULS Prague No. 20124301 and the project IGA FEM CULS Prague No. 20121041 .

\section{References}

Aldwin, C. M. and Yancura, L. 'Stress, Coping, and Adult Development' In Contrada, R. J. and Baum, A. (2011) The Handbook of Stress Science, New York: Springer Publishing Company.

Bandura, A. (1997). Self-efficacy: The exercise of control. New York: Freeman.

Bozoglan, B., Demirer, V., and Sahin, I. (2013) 'Loneliness, selfesteem, and life satisfaction as predictors of Internet addiction: A cross-sectional study among Turkish university students', Scandinavian Journal Of Psychology, vol. 54, no. 4, pp. 313319.

D‘Amico, S., Marano, A., Geraci, M., and Legge, E. (2013) 'Perceived Self-Efficacy and Coping Styles Related to Stressful Critical Life Events', Plos ONE, vol. 8, no. 7, pp. 1-7.

Diener, E., Nickerson, C., Lucas, R., E. and Sandvik, E. (2002) 'Dispositional affect and job outcomes', Social Indicators Research, vol. 59, no. 3, pp. 229-259.

Diener, E., Emmons, R. A., Larsen, R. J. and Griffin, S. (1985) 'The Satisfaction With Life Scale', Journal of Personality Assessment, vol. 49, no. 1, pp. 71-75.

Diener, E. and Diener, C. (1996) 'Most people are happy', Psychological Science, vol. 7, no. 3, pp.181-185.

Diener, E. (1994) 'Assessing subjective well-being: Progress and opportunities', Social Indicators Research, vol. 31, no. 2, pp. 103-157.

Diener, E. (2000) 'Subjective well-being: The science of happiness and a proposal for a national index', American Psychologist, vol. 55, no. 1, pp. 34-43.

Diener, E. (2012) 'New findings and future directions for subjective well-being research', American Psychologist, vol. 67 , no. 8, pp. 590-597.

Digdon, N. and Landry, K. (2013) 'University students' motives for drinking alcohol are related to evening preference, poor sleep, and ways of coping with stress', Biological Rhythm Research, vol. 44, no. 1, pp. 1-11.

Chýlová, H. and Natovová, L. (2013) 'Stress, Self-efficacy and Well-Being of the University Students - Part I: Gender Differences', Journal on Efficiency and Responsibility in Education and Science, [Electronic], vol. 6, no. 3, pp. 190-202, ISSN 1803-1617, Available: www.eriesjournal.com/_papers/ article_213.pdf, [30 Sep 2013].

Eroğlu, S. (2012) 'Examination of University Students' Subjective Well-being: A Crosscultural Comparison', International Journal Of Academic Research, vol. 4, no. 1, pp. 168-171.

Janke, W. and Erdmann, G. (2003) Strategie zvládání stresu SVF 78, Praha: Testcentrum.

Jerusalem, M. and Schwarzer, R. (1992) 'Self-efficacy as a resource factor in stress appraisal processes' In R. Schwarzer (Ed.) Self-efficacy: Thought control of action (pp. 195-213),
Washington: Hemisphere Publishing Corp.

Kausar, R. (2010) 'Perceived Stress, Academic Workloads and Use of Coping Strategies by University Students', Journal of Behavioural Sciences, vol. 20, no. 1, pp. 31-45.

Kebza, V. (2005) Psychosociální determinanty zdraví, Praha: Academia.

Křivohlavý, J., Schwarzer, R. and Jerusalem, M. (1993) Czech Adaptation of the General Self-Efficacy Scale, [online], available at: http://userpage.fu-berlin.de/ health/czec.htm, [cit. 7.3. 2013].

Lazarus, R. J. (1999) Stress and Emotion, New York: Springer Publishing Company.

Lipke, S. et al. (2009) 'Self-efficacy moderates the mediation on intentions into behaviour via plans', American Journal of Health Behavior, vol. 33, no. 5, pp. 521-529.

Loeb, S. J., Steffensmeier, D. and Kassab, C. (2011) 'Predictors of self-efficacy and self-rated health for older male inmates', Journal Of Advanced Nursing, vol. 67, no. 4, pp. 811-820.

Natovová, L., Chýlová, H. (2012) “Coping Strategies Adopted by University Students - Part II: Role Conflict and Age”, Journal on Efficiency and Responsibility in Education and Science, Vol. 5, No. 4, pp. 226-238, ISSN 1803-1617, [on-line] www. eriesjournal.com/_papers/article_195.pdf [2012-12-30]. doi: 10.7160/eriesj.2012.050405

Natovová, L. et al (2013) 'Coping, Self-efficacy and Behavioural Markers in Managing Stress at University Students', Proceedings of the 10th International Conference on Efficiency and Responsibility in Education (ERIE 2013), Prague, pp. 455460.

Nickerson, C., Diener, E. and Schwarz, N. (2011) ,Positive Affect and College Success', Journal of Happiness Studies, vol. 12, no. 4, pp. 717-746.

Pavot, W. and Diener, E. (2008) 'The Satisfaction With Life Scale and the emerging construct of life satisfaction', The Journal of Positive Psychology, vol. 3, no. 2, pp. 137-152.

Petegem, Van, K. et al. (2008) 'The influence of student characteristics and interpersonal teacher behaviour in the classroom on student's wellbeing', Social Indicators Research, vol. 85 , no. 2 , pp. $279-291$.

Robotham, D. and Julian, C. (2006) 'Stress and the higher education student: a critical review of the literature', Journal of Further \& Higher Education, vol. 30, no. 2, pp. 107-117.

Samuel, R., Bergman, M. and Hupka-Brunner, S. (2013) 'The Interplay between Educational Achievement, Occupational Success, and Well-Being', Social Indicators Research, vol. 111, no. 1, pp. 75-96. doi:10.1007/s11205-011-9984-5

Schreiber, V. (2000) Lidský stres. Praha: Academia.

Tanaka, M. et al. (2009) 'Stress and Coping Styles are Associated with Severe Fatigue in Medical Students', Behavioural Medicine, vol. 35, no. 3, pp. 87-92.

Warner, L. M. et al. (2011) 'Sources of Perceived Self-Efficacy as Predictors of Physical Activity in Older Adults', Applied Psychology: Health \& Well-Being, vol. 3, no. 2, pp. 172-192. 